\title{
Antiretroviral therapy initiated soon after HIV diagnosis as standard care: potential to save lives?
}

This article was published in the following Dove Press journal:

HIVIAIDS - Research and Palliative Care

28 January $201 \mathrm{I}$

Number of times this article has been viewed

\author{
Simon P Johnstone- \\ Robertson \\ John Hargrove \\ Brian G Williams \\ South African Centre for \\ Epidemiological Modelling \\ and Analysis, DST/NRF Centre \\ of Excellence in Epidemiological \\ Modelling and Analysis, \\ Stellenbosch, South Africa
}

Correspondence: Simon P JohnstoneRobertson

Desmond Tutu HIV Centre, Institute of Infectious Disease and Molecular Medicine, Faculty of Health Sciences, University of Cape Town, Anzio Road, Observatory 7925, Cape Town,

South Africa

Tel +27 2I 6506970

Fax +27216506963

Email spjohnstonerobertson@gmail.com

\begin{abstract}
In 2008, an estimated 33.4 million people were infected with human immunodeficiency virus (HIV) and $\sim 4$ million people were receiving antiretroviral therapy (ART). However, in 2007, an estimated 6.7 million people were in need of ART under the current World Health Organization guidelines, and 2.7 million more people became infected with HIV. Most of those not currently eligible for ART will become eligible within the next decade, making the current treatment strategy unsustainable. The development of cheaper, less toxic, and more potent antiretrovirals over the past decade has made it possible to consider novel strategies of arresting the HIV/AIDS epidemic. Evidence is growing that ART can be used to prevent HIV transmission and that earlier initiation of treatment is beneficial for those infected with HIV. A mathematical model predicts that by testing whole communities annually and treating all who are infected immediately, up to 7.2 million AIDS-related deaths could be prevented in the next 40 years, long-term funding required to fight the HIV epidemic could be reduced, and, most importantly, control of the HIV/ AIDS epidemic could be regained within 1-2 years of full-scale implementation of the strategy. We discuss the development of the concept of ART for the prevention of HIV transmission and the modeled impact that a test-and-treat strategy could have on the HIV epidemic, and consequently argue that a field trial should be carried out to confirm model parameters, highlight any practical problems, and test the model's predictions.
\end{abstract}

Keywords: human immunodeficiency virus (HIV), test-and-treat, mathematical model, transmission, prevention, elimination

\section{Introduction}

In 2008, an estimated 33.4 million people were living with human immunodeficiency virus (HIV), and the number of new infections reached 2.7 million. ${ }^{1}$ It has been suggested that unless HIV transmission is stopped now, the targets of universal access to treatment and care will not be achieved. ${ }^{2,3}$ Various interventions, including behavior change through education, condom promotion, treatment of sexually transmitted infections (STIs), needle exchange programs, voluntary counseling and testing, and male circumcision, have been implemented in an attempt to stop the expansion of the HIV epidemic. Most have shown promise, but low uptake, poor adherence, and slow rollout have often frustrated the best efforts of public health authorities. ${ }^{4-8}$ Even the more effective interventions, such as male circumcision, which offers a $40 \%$ reduction in transmission at the population level, could not, by themselves, reduce HIV incidence sufficiently to rein in the epidemic completely. ${ }^{9}$ Only recently has a tenofovir-containing vaginal microbicide gel been shown to provide some protection to women. ${ }^{10}$ The development of an HIV vaccine remains a distant hope in spite of recent progress. ${ }^{11,12}$ 
New approaches are needed if the epidemic is to be stopped, and there has been renewed interest in the possibility of universal voluntary HIV testing with immediate treatment (test-and-treat) for the prevention of HIV transmission. ${ }^{13-15}$ This would typically involve, in high prevalence settings, annual testing of presumptively HIV-negative people, together with the subsequent offering of immediate antiretroviral therapy (ART) and appropriate follow-up to all people infected with HIV. Those found to be HIV positive and placed on treatment (particularly acutely infected patients and patients with unstable viral loads) would require more frequent testing to monitor treatment adherence and provide early warning of the development of possible drug resistance. By placing all those infected with HIV on ART, as opposed to just those who meet current clinically defined stages of disease or who have a $\mathrm{CD}^{+}$count below 350 cells $/ \mu \mathrm{L}$, it has been estimated that transmission would be dramatically reduced. ${ }^{16,17}$ The intention of such a strategy, made possible through the development of cheaper, more effective, and less toxic drug regimens over the last decade, ${ }^{15,18-20}$ would be to stop transmission from infected to noninfected individuals and consequently drive HIV incidence rapidly toward zero.

ART dramatically reduces mortality in people living with HIV, ${ }^{21-23}$ but the potential for ART to reduce transmission is less certain. ${ }^{15,24-26}$ Given that ART, when taken as recommended, reduces viral load by several orders of magnitude, ${ }^{27-29}$ it shows promise as a means of reducing transmission. The population-level impact on transmission is still to be established, though. We review here the evidence for and against the use of a test-and-treat strategy for the prevention of transmission of HIV. We discuss the potential population-level impact and questions pertaining to testing frequency, timing of treatment initiation for those testing positive, and the tradeoff between high short-term costs and potential long-term savings resulting from implementation of mass HIV testing and treatment. ${ }^{16}$ We also discuss concerns that have been raised in the literature and conclude that there is an urgent need for a field trial to further evaluate the plausibility of such a strategy.

\section{ART for prevention}

The biological plausibility of using ART for the prevention of HIV transmission stems from the facts that transmission of HIV from infected to uninfected people takes place largely through exposure to bodily fluids, ${ }^{30-32}$ that viral load in these fluids largely determines the risk of transmission, ${ }^{33,34}$ and that the use of ART has been shown to reduce HIV-1 RNA concentration in both blood and seminal plasma by up to six orders of magnitude..$^{16,28,29,35-37}$ Furthermore, as the viral load in blood plasma is correlated with the viral load in semen and vaginal secretions, ${ }^{38} \mathrm{ART}$ also reduces the concentration of HIV-1 RNA in the female genital tract. ${ }^{39}$

Proof of concept comes from the fact that mother-tochild (MTC) transmission has virtually been eliminated in developed countries, where universal voluntary HIV testing and ART provision are now commonplace. ${ }^{40,41}$ Maternal plasma HIV-1 RNA concentration has long been recognized as the major determinant of MTC HIV transmission, ${ }^{42}$ so prevention of vertical transmission has been made possible by reducing the viral loads of HIV-positive mothers through the widespread distribution and use of ART. ${ }^{43,44}$

If ART is to have a similar impact on the overall HIV epidemic, it must prevent the most predominant form of transmission, namely heterosexual transmission. Studies in Thailand and Uganda have shown that transmission in heterosexual, HIV-serodiscordant couples depends strongly on the viral load within the infected partner, and no transmission events were observed when the infected person had an HIV-1 RNA plasma concentration of $<1000$ copies $/ \mathrm{mL} .{ }^{33,45}$ Similarly, a third study reported that viral load and positive viral isolation in culture were both risk factors for heterosexual transmission of HIV-1. ${ }^{46}$ In Spain, transmission decreased by $86 \%$ in those heterosexual, serodiscordant couples where the infected person was on ART. ${ }^{47}$ Similar results were obtained in Italy, before triple therapy became available, where zidovudine monotherapy was found to reduce transmission by $50 \%{ }^{48}$ These results suggest that mass rollout of ART could be used to effect major reductions in heterosexual transmission.

The mass rollout of ART for prevention has nonetheless been received with some skepticism. Of particular concern is the possibility that behavioral disinhibition among those on ART will increase their risk of infection and nullify the benefits of treatment. ${ }^{49-51}$ Several modeling studies have suggested that even modest increases in risky behavior would be sufficient to negate any potential decrease in HIV incidence. ${ }^{24,52-54}$ However, if ART reduces transmission by 10 times or more, behavioral disinhibition would have to increase transmission by 10 times or more, which is unlikely, and there is evidence that these fears may be exaggerated. In Taiwan, where policy was adopted in 1997 to provide every person living with HIV free access to ART, a population-level decrease in transmission of $53 \%$ was observed by $2002 . .^{55}$ The incidence of syphilis, used as a marker for behavioral risk compensation during this period, remained unchanged. ${ }^{55}$ Similar results have 
also been reported for British Columbia, where new HIV infections between 1995 and 1998 decreased by 50\%, despite an increase in syphilis rates. ${ }^{15}$ A review of 25 studies including heterosexual men and women, homosexual men, and intravenous drug users, furthermore showed no overall increase in risky sexual behavior among those receiving ART, even when therapy achieved an undetectable viral load. ${ }^{56}$ In Africa, ART has been associated with a decrease in risky sexual behavior. In Uganda, starting people on ART reduced the likelihood that they would engage in risky sexual behavior by as much as $50 \%-70 \% .^{25,57} \mathrm{~A} 7$-year study in South Africa also found that after ART initiation, people had less unprotected sex and fewer concurrent sexual partners. ${ }^{58}$ It has been suggested that the widespread provision of ART may result in increased contact between health care providers and treated patients, facilitating greater opportunity to encourage safe sexual practices, which would further reinforce prevention efforts. ${ }^{56,59}$ This evidence suggests that ART for prevention should be seriously reconsidered.

Under current guidelines, ART is administered on immunologically and clinically defined disease status, with the focus being the reduction of morbidity and mortality. ${ }^{17}$ Consequently, ART is generally given only to those whose immune system is already severely compromised. ${ }^{16,60}$ The extended length of time it takes for a patient's $\mathrm{CD}^{+}$count to fall below the recommended threshold for treatment initiation means that an infected person's period of infectivity is very long, so ample opportunity exists during which transmission may take place. ${ }^{3}$ Ignorance of HIV status, as well as low treatment coverage, further exacerbates the situation. ${ }^{2,3,61,62}$ The current strategy is therefore not able to reduce transmission, even if perfect implementation was possible.

Along with reducing transmission, the evidence is that early treatment also improves the prognosis for the treated individual. Early treatment was first advocated by Ho, ${ }^{63}$ mainly in relation to the potential benefit for infected individuals, because of the following reasons. First, the viral population in newly infected cases tends to be homogeneous, making it less likely to contain drug-resistant variants and therefore more susceptible to effective treatment regimens. Second, the number of virions produced during a single month of acute infection approximates the number produced during several years of asymptomatic chronic infection, so treatment just after seroconversion may be more efficient and could therefore have a greater effect than delayed treatment. Third, the plateau concentration of plasma viral RNA has been shown to be predictive of the long-term clinical outcome of an infected individual, so by treating patients soon after seroconversion, the initial set point viral load could be lowered and the clinical outcome thereby improved. ${ }^{63}$

Further individual benefit of early treatment initiation derives from the fact that uncontrolled HIV replication appears to contribute to non-AIDS-defining complications, including disease of the liver, kidney, and cardiovascular system and non-AIDS malignancies. ${ }^{64}$ Earlier treatment of $\mathrm{HIV}$-infected patients could serve to reduce the frequency of occurrence of such complications, subsequently improving the general health of infected individuals. In Zimbabwe, increased rates of mortality among HIV-positive postpartum women, compared with those who are HIV negative, along with identified causes of death, suggest that early initiation of ART could prevent $50 \%-90 \%$ of deaths in HIV-positive postpartum women. ${ }^{65}$ In particular, this was true for postpartum women who would not qualify for ART under the current ART treatment guideline of a $\mathrm{CD}^{+}$count below 350 cells $/ \mu \mathrm{L} .{ }^{65}$

A further argument for the use of ART for prevention was provided by Montaner et al, who used UNAIDS regional statistics to show that the ratio of new HIV infections to prevalent cases correlated inversely to the availability of ART in each region. ${ }^{15}$ The effect of ART on transmission was subsequently estimated for those regions where ART was widely available. Using the same methodology as that presented by Montaner et al, one would expect between 1.2 and 2 million new infections to be prevented annually by mass rollout of ART in those areas where incidence is $>8 \%$ of prevalence. This equates to a total long-term saving of US\$296-493 billion in treatment costs, based on the same estimated cost for lifetime treatment of US\$241,000 used by Montaner et al. ${ }^{15}$ The limitations of this kind of argument include the unknown accuracy of regional incidence and prevalence data, the assumption that the number of transmitted cases was directly proportional to the number of prevalent cases, and the fact that ART may be only one of several factors contributing to the lower incidence to prevalence ratios seen in some regions. Nevertheless, it offers a glimpse of the potential impact ART may have on HIV transmission in those areas where ART is still not readily available, as well as the possible financial savings that could accompany it.

\section{The modeled impact of ART for prevention}

Given the established potential for ART to prevent HIV transmission and the failure of current interventions to produce significant reductions in HIV incidence, Granich et al sought to model the impact a test-and-treat strategy would 
have on the HIV epidemic. ${ }^{16}$ The strategy would involve diagnosing all those infected with HIV as soon as possible after infection and immediately offering ART to all who test positive. Its impact was modeled in the context of a generalized heterosexual epidemic, with a magnitude similar to that found in southern Africa, and was described in terms of the expected decrease in incidence.

\section{Stochastic model}

When any intervention is implemented, the hope is that incidence will be sufficiently reduced to eliminate the epidemic. Granich et al defined elimination as incidence of $<1$ HIV infection per 1000 people per year, ${ }^{16}$ which would require that the basic reproductive number $R_{0}$ (the number of secondary infections resulting when a single infectious case is introduced into a completely susceptible population) be reduced to, and kept, below $1 .{ }^{66}$ Granich et al constructed a stochastic model to determine how frequently people would have to be tested for HIV infection and how soon after testing positive they would need to be placed on treatment, so that $\mathrm{R}_{0}$ could be brought below unity and the HIV epidemic eliminated.

After calibrating the stochastic model to a South African epidemic, where $R_{0}=7$ prior to the introduction of ART, ${ }^{67}$ the amount by which $R_{0}$ would decrease was shown to depend on both testing frequency and $\mathrm{CD} 4^{+}$count at which ART would be started in those testing HIV positive. It was shown that for $R_{0}$ to be brought below 1 , universal voluntary HIV testing would have to be conducted at least once a year and ART would have to be initiated, at the latest, when an infected person's $\mathrm{CD}^{+}$count drops below 900 cells $/ \mu \mathrm{L}$. Because the mean $\mathrm{CD}^{+}{ }^{+}$count immediately after seroconversion in South Africa is just below 900 cells/ $\mu \mathrm{L},{ }^{67}$ ART would effectively have to be initiated as soon as possible after diagnosis. Anything short of this and the basic reproductive number will remain above 1 , resulting in an epidemic that persists.

\section{Deterministic transmission model}

The time-dependent impact of the test-and-treat strategy on the South African HIV epidemic was modeled using an ordinary differential equation (ODE) deterministic transmission model. In particular, the impact it would have was compared with that expected for the current strategy, where ART should be initiated when an infected person's $\mathrm{CD}^{+}{ }^{+}$count falls below 350 cells $/ \mu \mathrm{L}$. The authors calculated the number of deaths averted and the funding required for each strategy and compared the latter with UNAIDS estimates of global funding needed for universal access to be achieved. They also estimated the time for elimination to be achieved after implementation of the test-and-treat strategy.

Once the deterministic transmission model was calibrated to South African national antenatal clinic prevalence data for people aged 15 years and above, ART was introduced in order to determine the impact it would have on a predominantly heterosexual epidemic. Under the current strategy of starting ART once $\mathrm{CD}^{+}$count falls below 350 cells $/ \mu \mathrm{L}$, the incidence and prevalence of those not on ART decreased by $\sim 30 \%$. Mortality decreased by an even greater margin because everyone, apart from those who refused treatment, started ART when their $\mathrm{CD}^{+}$cell count fell below this level. ${ }^{16}$ The rate at which people started ART and the mortality of those on ART were shown to peak at $0.08 \%$ /year in 2014 and $0.8 \%$ /year in 2020, respectively. The proportion of people on ART would be expected to reach a maximum of $5 \%$ in 2020 .

Introducing ART, at the intensity prescribed by the stochastic model for the test-and-treat strategy, illustrated that such a strategy would reduce the incidence, prevalence, and mortality of those not on ART to negligible levels. The rate at which people would be placed on ART is expected to increase and peak at $0.5 \%$ /year in 2010 , which reflects the fact that every HIV-infected person would be eligible for treatment. All those receiving ART would require treatment until the end of their natural lives, however, so that the proportion of people on ART would increase and peak at around $12 \%$ in 2014 . In spite of this, by 2016, there would be fewer people starting ART, and by 2030 fewer people receiving ART, than there would be with the current strategy. This would be a direct result of the ART-associated reduction in transmission. Mortality of those on ART was similar until 2016 for the two strategies, when mortality for the test-and-treat strategy is expected to reach its peak at $0.5 \% /$ year and subsequently start to decline, whereas that of the current strategy would continue to rise considerably for at least another 5 years.

The most important result of any intervention is the number of lives that can be expected to be saved. Excluding all forms of intervention from the ODE model, it was estimated that just over 11 million AIDS-related deaths would occur between 2008 and 2050. By including the current treatment strategy of ART for those infected individuals whose $\mathrm{CD}^{+}$count is below 350 cells/ $\mu \mathrm{L}$ in the ODE model, this number could be reduced to 8.6 million, so 2.4 million lives would be saved. Under the test-and-treat strategy, the number of AIDS-related deaths averted in the same time 
period was estimated at 7.2 million, so fewer than 4 million HIV-related deaths would occur in the next four decades.

The time required for the HIV epidemic to be eliminated, after rollout of the test-and-treat strategy, was found to depend on both the starting time of the rollout and the rate at which rollout takes place. If rollout had begun in 2008, and had been fully scaled up by 2016, elimination would have been achieved by 2014, ie, within 6 years of the strategy being started. The time to elimination is an important aspect of the intervention because it informs policy makers when they can expect to start seeing a return on their investment, in the form of savings in treatment costs resulting from reduced numbers of people being treated. Moreover, it informs health providers of how long it will be before focus has to be shifted from prevention of transmission to management of people already infected. Finally, it is important epidemiologically because it indicates the time until the epidemic is brought under control.

Granich et al calculated the potential costs of both the testand-treat and the current strategy and compared them with the UNAIDS estimate of funds needed to provide universal access to prevention, care, and treatment in South Africa, where $17 \%$ of the global HIV/AIDS burden exists. ${ }^{1,16,68}$ It was assumed that first-line and second-line therapy would cost US\$727/year and US\$3290/year, respectively, both of which would include drug delivery, HIV and laboratory testing, and patient management. The model indicated that test-and-treat would initially be about three times as expensive as the current strategy, costing US\$3.4 billion in 2015. Thereafter, however, the cost of the test-and-treat strategy would decline, whereas the current strategy would continue to rise as more people require ART. By 2034, the test-and-treat strategy would cost less annually than the current strategy. Furthermore, it would cost less than the US $\$ 8.84$ billion/year estimated by UNAIDS to achieve universal access to prevention, care, and treatment in South Africa by 2015. These results are better than the initial estimates proposed by Montaner et al in which the cost of treating all HIV-infected people in the first year, assuming there would be no new infections taking place afterward, amounted to an average annual cost of US\$ 7 billion. ${ }^{15}$ In the short term the test-and-treat strategy will be costly, but in the long term it will be cost effective due to the huge number of infections that are prevented in years to come.

\section{Universal voluntary HIV testing and immediate treatment: the challenges and benefits}

Major challenges facing the implementation of the test-andtreat strategy relate primarily to the sheer numbers involved, creating even greater obstacles than those seen in current ART scale-up programs, as many people infected with HIV would qualify for ART. ${ }^{15}$ Where health infrastructure is weak, it would need to be strengthened to cope with the increase in demand. Adequate training of health care workers, as well as ensuring the continuous supply of drugs and other resources, will form an integral part of this process. One suggested means of reducing the potential burden would initially be to focus mass HIV testing on the most-at-risk populations, namely those people infected with tuberculosis (TB) or sexually transmitted diseases, and pregnant women. ${ }^{69}$ It is important that rural populations not be neglected, though, and relevant ways of reaching these populations must therefore also be considered. Despite the expected increase in demand on health services, increased numbers of HIV-infected people having access to ART will result in a decrease in morbidity. This will go some way to alleviate the increased burden on health systems, freeing human resources and capacity in the long run. ${ }^{16}$ A clear programmatic advantage of the strategy is that there would be only one criterion for a person to be placed on treatment, namely HIV status. The fact that $\mathrm{CD}^{+}$ cell count or viral load would not be considered would free up a significant amount of human and financial resources.

The success of the test-and-treat strategy will depend on its acceptability and uptake by the populations in which it is implemented. In the model presented by Granich et al, it was assumed that all adults in a community would be tested for HIV once a year, on average, and that those diagnosed as HIV positive would start ART immediately, irrespective of $\mathrm{CD}^{+}{ }^{+}$cell count. ${ }^{16}$ A refusal rate was incorporated into the model to take into account those who refused treatment. High rates of acceptability and uptake will only realistically be possible through community education and awareness campaigns that encourage HIV testing. Even in a country such as the US, where HIV testing is widely available, $25 \%$ of infected individuals still do not know their status $;^{70}$ the figure for Sub-Saharan Africa is $78 \% .^{2}$ The education and awareness campaigns could also be used to encourage uptake of immediate treatment after testing so that refusal rates are kept to a minimum. Steps must also be taken to ensure that coercion is prevented and that the human rights of individuals being tested and placed on treatment are protected. Appropriate training, engagement with the community, and supervision should be sufficient to keep such problems to a minimum.

Once patients have been tested and placed on treatment, there will be the challenge of managing patient adherence and change in risky behavior. Data from Malawi and elsewhere 
indicate that good levels of adherence are achievable in both resource-limited settings and marginalized populations in developed countries, suggesting little reason to believe that adherence would be reduced if adequate patient support and treatment literacy are provided. ${ }^{71-73}$ Others have argued, however, that current data are indicative only of those seeking treatment because they are sick, whereas implementing the test-and-treat strategy would include placing on treatment those who still feel well, so the levels of adherence assumed in Granich et al's model would be difficult to achieve. ${ }^{74}$ Either way, appropriate management of patient adherence will be necessary practice to ensure the effectiveness of early treatment. With regard to behavioral risk compensation, the evidence available indicates that it is unlikely to be important in Africa and other areas where heterosexual transmission is predominant. ${ }^{59}$ It has been suggested that as better contact between treated patients and their health care providers increases the opportunities for the prevention of secondary transmission, it may even be possible to decrease levels of risky behavior. ${ }^{59}$ Behavior should nonetheless be monitored because the behavioral implications of a large cohort of people receiving ART is still uncertain. Monitoring increases in risky behavior could be accomplished by observing changes in the rates of STIs, ${ }^{55}$ while simultaneously monitoring any potential for coinfection of HIV and STIs to re-establish the infectiousness of HIV patients on ART. ${ }^{59,74}$ Patient management will therefore play an important role in the test-and-treat strategy and will serve to ensure that risky behavior and STIs will not undermine the ability of ART to prevent transmission.

Drug regimens will form an integral part of the strategy of treatment for prevention. For the strategy to have the impact proposed, it will be necessary for the latest, most effective regimens to be accessible in all countries. ${ }^{70}$ Such regimens will need to be cheap and easy for patients to take and have low toxicity. ${ }^{16}$ First-line regimens such as these are now available, increasing the feasibility of the strategy. ${ }^{15,18,19,75}$ Potent second- and third-line regimens with similar characteristics will also be required so that if first-line drug resistance develops in patients, the regimens required to maintain viral load suppression will be readily available. Second-line regimens are currently still significantly more expensive than their first-line counterparts. ${ }^{16,20}$ Mass rollout of these drugs, however, can be expected to cause a drop in regimen prices as simpler and cheaper generic regimens are developed and as supply chains are strengthened. The choice of appropriate drug regimens and decisions on how they will be best administered operationally and clinically will need careful consideration prior to the start of any intervention.
The approaches, moreover, are likely to vary with location and circumstance. In each case, the choice will need to be made in such a way as to ensure minimal side effects, low rates of failure, and maximal adherence.

Similarly, although the default approach will be to offer ART to all HIV-positive people, this decision would be in the hands of individual clinicians who could modify this decision on the basis of additional information on particular patients. Careful monitoring of patients will also be essential to ensure the early detection of any adverse events.

Drug resistance should be monitored closely and continuously on implementation of the test-and-treat strategy. Mathematical models initially predicted that transmitted resistance will increase with the proportion of HIV-infected people receiving ART. ${ }^{59}$ It has been reported, however, that drug-resistant HIV may be less transmissible than drugsusceptible strains. ${ }^{76}$ There is also empirical evidence that the suppression of HIV RNA on a population level is associated with a decrease in drug resistance. ${ }^{77}$

The implementation of the test-and-treat strategy will produce a rapid decline in HIV incidence and mortality and thus a shift in focus, from ensuring that everyone infected is placed on treatment to managing patient adherence and minimizing transmitted resistance. ${ }^{16}$ HIV prevalence would also decline, but only at a later stage, when the cohort receiving ART starts to age and die. Granich et al modeled an epidemic similar to that found in South Africa, where HIV prevalence is high. In low prevalence settings, it will not be efficient to test entire populations for HIV. ${ }^{16}$ The intensity and frequency with which such a strategy would need to be implemented will thus vary with the epidemiological context and cohort of patients being treated. ${ }^{3,74}$ The establishment of worldwide-accepted criteria of patients' enrollment and monitoring in this regard is essential to the efficacy and success of such a strategy.

Despite the intensive screening implicit in the test-andtreat strategy, it is likely that some HIV-infected people would still be missed, facilitating the persistence of small pockets of transmission among those with high risk. ${ }^{74}$ It is therefore important that the strategy initially focuses on those at high risk of infection as it is rolled out, so that these "transmission pockets" are kept to a minimum.

A concern that has been raised with respect to the proposed strategy is whether or not it could be implemented in the face of widespread HIV-related stigma. It has even been suggested that the strategy could serve to increase stigma if partial success led to HIV becoming associated with particular subpopulations. ${ }^{78}$ Others have argued that the opposite would in fact be true: that the strategy could play a significant part 
in reducing HIV-related stigma by raising awareness of HIV and the drugs available for treatment and by encouraging HIV infection to be regarded in the same manner as any other infection..$^{79}$ This, it was suggested, could go a long way to removing HIV-associated fear and discrimination. The potential for the strategy to shift the benefits of treatment from the individual to the general population was another concern that was raised. Growing evidence for the individual's benefit of earlier treatment has, however, been established.

An important benefit of the test-and-treat strategy lies in its potential for significantly reducing coinfections; ${ }^{79,80}$ in particular, it may go a long way toward arresting the tuberculosis epidemic. ${ }^{81}$ Other potential benefits are likely to include decreased deaths resulting from late diagnosis, further prevention of MTC transmission, and the reinforcement of current efforts to provide universal access to ART.,260,65

\section{Conclusion}

The mathematical model published by Granich et al indicates that the test-and-treat strategy could have a big impact on the HIV epidemic. In particular, it is estimated that the strategy could prevent up to 7.2 million AIDS-related deaths in the next 40 years if implemented in conjunction with other interventions already in place. Such a strategy would require large initial financial investment but would become more cost effective than the current treatment strategy within 30 years of rollout. The immediate priority is a field trial aimed at addressing uncertainties regarding model parameters and determining any practical issues that would need to be considered more carefully before large-scale implementation of the strategy can take place. A field trial would also serve to acquire the empirical data needed to guide national ART programs and would go a long way toward determining whether the test-and-treat strategy will have the impact on the HIV epidemic that has been modeled.

\section{Disclosure}

The authors report no conflicts of interest in this work.

\section{References}

1. UNAIDS. AIDS Epidemic Update: December 2009. Geneva: UNAIDS; 2009.

2. WHO. Towards Universal Access: Scaling Up Priority HIV/AIDS Interventions in the Health Sector: Progress Report, September 2009. Geneva: World Health Organization; 2009.

3. De Cock KM, Gilks CF, Lo YR, Guerma T. Can antiretroviral therapy eliminate HIV transmission? Lancet. 2009;373(9657):7-9.

4. Wood E, Tyndall MW, Spittal PM, et al. Factors associated with persistent high-risk syringe sharing in the presence of an established needle exchange programme. AIDS. 2002;16(6):941-943.

5. Malonza IM, Richardson BA, Kreiss JK, Bwayo JJ, Stewart GC. The effect of rapid HIV-1 testing on uptake of perinatal HIV-1 interventions: a randomized clinical trial. AIDS. 2003;17(1):113-118.
6. Temmerman M, Quaghebeur A, Mwanyumba F, Mandaliya K. Motherto-child HIV transmission in resource poor settings: how to improve coverage? AIDS. 2003;17(8):1239-1242.

7. Gayle HD. Expanding access to HIV prevention. AIDS Res Ther. 2006;3:2.

8. Stover J, Fahnestock M. Coverage of Selected Services for HIV/AIDS Prevention, Care, and Treatment in Low-and Middle-Income Countries in 2005. Washington (DC): Constella Futures, POLICY Project; 2006.

9. Williams BG, Lloyd-Smith JO, Gouws E, et al. The potential impact of male circumcision on HIV in sub-Saharan Africa. PLoS Med. 2006; 3(7):e262.

10. Abdool Karim Q, Abdool Karim SS, Frohlich JA, et al. Effectiveness and safety of tenofovir gel, an antiretroviral microbicide, for the prevention of HIV infection in women. Science. 2010;329(5996):1168-1174.

11. Weiss RA. Special anniversary review: twenty-five years of human immunodeficiency virus research: successes and challenges. Clin Exp Immunol. 2008;152(2):201-210.

12. Rerks-Ngarm S, Pitisuttithum P, Nitayaphan S, et al. Vaccination with ALVAC and AIDSVAX to prevent HIV-1 infection in Thailand. $N$ Engl J Med. 2009;361(23):2209-2220.

13. Bunnell R, Mermin J, de Cock KM. HIV prevention for a threatened continent: implementing positive prevention in Africa. JAMA. 2006; 296(7):855-858.

14. Hosseinipour M, Cohen MS, Vernazza PL, Kashuba AD. Can antiretroviral therapy be used to prevent sexual transmission of human immunodeficiency virus type 1? Clin Infect Dis. 2002;34(10): 1391-1395.

15. Levy AR, James D, Johnston KM, et al. The direct costs of HIV/AIDS care. Lancet Infect Dis. 2006;6(3):171-177.

16. Granich RM, Gilks CF, Dye C, de Cock KM, Williams BG. Universal voluntary HIV testing with immediate antiretroviral therapy as a strategy for elimination of HIV transmission: a mathematical model. Lancet. 2009;373(9657):48-57.

17. Gilks CF, Crowley S, Ekpini R, et al. The WHO public-health approach to antiretroviral treatment against HIV in resource-limited settings. Lancet. 2006;368(9534):505-510.

18. Staszewski S, Morales-Ramirez J, Tashima KT, et al. Efavirenz plus zidovudine and lamivudine, efavirenz plus indinavir, and indinavir plus zidovudine and lamivudine in the treatment of HIV-1 infection in adults. Study 006 Team. N Engl J Med. 1999;341(25): 1865-1873.

19. Gallant JE, DeJesus E, Arribas JR, et al. Tenofovir DF, emtricitabine, and efavirenz vs zidovudine, lamivudine, and efavirenz for HIV. NEngl J Med. 2006;354(3):251-260.

20. Médecins Sans Frontières. Untangling the Web of Antiretroviral Price Reductions. 13th ed. Médecins Sans Frontières Report; 2010. Available from: http://utw.msfaccess.org/. Accessed Dec 172010.

21. Jahn A, Floyd S, Crampin AC, et al. Population-level effect of HIV on adult mortality and early evidence of reversal after introduction of antiretroviral therapy in Malawi. Lancet. 2008;371(9624):1603-1611.

22. Murphy EL, Collier AC, Kalish LA, et al. Highly active antiretroviral therapy decreases mortality and morbidity in patients with advanced HIV disease. Ann Intern Med. 2001;135(1):17-26.

23. Violari A, Cotton MF, Gibb DM, et al. Early antiretroviral therapy and mortality among HIV-infected infants. $N$ Engl J Med. 2008;359(21): 2233-2244.

24. Velasco-Hernandez JX, Gershengorn HB, Blower SM. Could widespread use of combination antiretroviral therapy eradicate HIV epidemics? Lancet Infect Dis. 2002;2(8):487-493.

25. Bunnell R, Ekwaru JP, Solberg P, et al. Changes in sexual behavior and risk of HIV transmission after antiretroviral therapy and prevention interventions in rural Uganda. AIDS. 2006;20(1):85-92.

26. Baggaley RF, Garnett GP, Ferguson NM. Modelling the impact of antiretroviral use in resource-poor settings. PLoS Med. 2006;3(4):e124

27. Kilby JM, Lee HY, Hazelwood JD, et al. Treatment response in acute/ early infection versus advanced AIDS: equivalent first and second phases of HIV RNA decline. AIDS. 2008;22(8):957-962. 
28. Vernazza PL, Gilliam BL, Flepp M, et al. Effect of antiviral treatment on the shedding of HIV-1 in semen. AIDS. 1997;11(10):1249-1254.

29. Gupta P, Mellors J, Kingsley L, et al. High viral load in semen of human immunodeficiency virus type 1 -infected men at all stages of disease and its reduction by therapy with protease and nonnucleoside reverse transcriptase inhibitors. J Virol. 1997;71(8):6271-6275.

30. Dunn DT, Newell ML, Ades AE, Peckham CS. Risk of human immunodeficiency virus type 1 transmission through breastfeeding. Lancet. 1992;340(8819):585-588.

31. Ward JW, Holmberg SD, Allen JR, et al. Transmission of human immunodeficiency virus (HIV) by blood transfusions screened as negative for HIV antibody. N Engl J Med. 1988;318(8):473-478.

32. Cameron DW, Simonsen JN, D'Costa LJ, et al. Female to male transmission of human immunodeficiency virus type 1: risk factors for seroconversion in men. Lancet. 1989;2(8660):403-407.

33. Quinn TC, Wawer MJ, Sewankambo N, et al. Viral load and heterosexual transmission of human immunodeficiency virus type 1. Rakai Project Study Group. N Engl J Med. 2000;342(13):921-929.

34. Sperling RS, Shapiro DE, Coombs RW, et al. Maternal viral load, zidovudine treatment, and the risk of transmission of human immunodeficiency virus type 1 from mother to infant. Pediatric AIDS Clinical Trials Group Protocol 076 Study Group. N Engl J Med. 1996;335(22): 1621-1629.

35. Hogg RS, Rhone SA, Yip B, et al. Antiviral effect of double and triple drug combinations amongst HIV-infected adults: lessons from the implementation of viral load-driven antiretroviral therapy. AIDS. 1998;12(3):279-284.

36. Vernazza PL, Gilliam BL, Dyer J, et al. Quantification of HIV in semen: correlation with antiviral treatment and immune status. AIDS. 1997;11(8):987-993.

37. Marconi VC, Grandits GA, Weintrob AC, et al. Outcomes of highly active antiretroviral therapy in the context of universal access to healthcare: the US Military HIV Natural History Study. AIDS Res Ther. 2010;7(1):14.

38. Hart CE, Lennox JL, Pratt-Palmore M, et al. Correlation of human immunodeficiency virus type 1 RNA levels in blood and the female genital tract. J Infect Dis. 1999;179(4):871-882.

39. $\mathrm{Cu}-\mathrm{Uvin} \mathrm{S}$, Caliendo AM, Reinert S, et al. Effect of highly active antiretroviral therapy on cervicovaginal HIV-1 RNA. AIDS. 2000;14(4): $415-421$.

40. Centers for Disease Control and Prevention (CDC). Achievements in public health. Reduction in perinatal transmission of HIV infection - United States, 1985-2005. MMWR Morb Mortal Wkly Rep. 2006;55(21):592-597.

41. European Collaborative Study. Mother-to-child transmission of HIV infection in the era of highly active antiretroviral therapy. Clin Infect Dis. 2005;40(3):458-465.

42. Fang G, Burger H, Grimson R, et al. Maternal plasma human immunodeficiency virus type 1 RNA level: a determinant and projected threshold for mother-to-child transmission. Proc Natl Acad Sci U SA. 1995;92(26):12100-12104.

43. Guay LA, Musoke P, Fleming T, et al. Intrapartum and neonatal single-dose nevirapine compared with zidovudine for prevention of mother-to-child transmission of HIV-1 in Kampala, Uganda: HIVNET 012 randomised trial. Lancet. 1999;354(9181):795-802.

44. De Cock KM, Fowler MG, Mercier E, et al. Prevention of mother-tochild HIV transmission in resource-poor countries: translating research into policy and practice. JAMA. 2000;283(9):1175-1182.

45. Tovanabutra S, Robison V, Wongtrakul J, et al. Male viral load and heterosexual transmission of HIV-1 subtype E in northern Thailand. J Acquir Immune Defic Syndr. 2002;29(3):275-283.

46. Pedraza MA, del Romero J, Roldán F, et al. Heterosexual transmission of HIV-1 is associated with high plasma viral load levels and a positive viral isolation in the infected partner. J Acquir Immune Defic Syndr. 1999;21(2):120-125.
47. Castilla J, del Romero J, Hernando V, Marincovich B, García S, Rodríguez C. Effectiveness of highly active antiretroviral therapy in reducing heterosexual transmission of HIV. J Acquir Immune Defic Syndr. 2005;40(1):96-101.

48. Musicco M, Lazzarin A, Nicolosi A, et al. Antiretroviral treatment of men infected with human immunodeficiency virus type 1 reduces the incidence of heterosexual transmission. Italian Study Group on HIV Heterosexual Transmission. Arch Intern Med. 1994;154(17):1971-1976.

49. Van de Ven P, Prestage G, Crawford J, Grulich A, Kippax S. Sexual risk behaviour increases and is associated with HIV optimism among HIV-negative and HIV-positive gay men in Sydney over the 4 year period to February 2000. AIDS. 2000;14(18):2951-2953.

50. Van de Ven P, Kippax S, Knox S, Prestage G, Crawford J. HIV treatments optimism and sexual behaviour among gay men in Sydney and Melbourne. AIDS. 1999;13(16):2289-2294.

51. Centers for Disease Control and Prevention (CDC). Increases in unsafe sex and rectal gonorrhea among men who have sex with men - San Francisco, California, 1994-1997. MMWR Morb Mortal Wkly Rep. 1999;48(3):45-48.

52. Blower SM, Gershengorn HB, Grant RM. A tale of two futures: HIV and antiretroviral therapy in San Francisco. Science. 2000;287(5453): 650-654.

53. Law MG, Prestage G, Grulich A, van de Ven P, Kippax S. Modelling the effect of combination antiretroviral treatments on HIV incidence. AIDS. 2001;15(10):1287-1294.

54. Blower S, Farmer P. Predicting the public health impact of antiretrovirals: preventing HIV in developing countries. AIDScience. 2003;3(11). Available from: $h$ ttp://aidscience.org/Articles/AIDScience033.asp. Accessed December 17, 2010.

55. Fang CT, Hsu HM, Twu SJ, et al. Decreased HIV transmission after a policy of providing free access to highly active antiretroviral therapy in Taiwan. J Infect Dis. 2004;190(5):879-885.

56. Crepaz N, Hart TA, Marks G. Highly active antiretroviral therapy and sexual risk behavior: a meta-analytic review. JAMA. 2004;292(2): 224-236.

57. Bechange S, Bunnell R, Awor A, et al. Two-year follow-up of sexual behavior among HIV-uninfected household members of adults taking antiretroviral therapy in Uganda: no evidence of disinhibition. AIDS Behav. 2010;14(4):816-823.

58. Venkatesh KK, de Bruyn G, Lurie MN, et al. Decreased sexual risk behavior in the era of HAART among HIV-infected urban and rural South Africans attending primary care clinics. AIDS. 2010; 24(17):2687-2696

59. Blower S, Bodine E, Kahn J, McFarland W. The antiretroviral rollout and drug-resistant HIV in Africa: insights from empirical data and theoretical models. AIDS. 2005;19(1):1-14

60. Lawn SD, Harries AD, Anglaret X, Myer L, Wood R. Early mortality among adults accessing antiretroviral treatment programmes in subSaharan Africa. AIDS. 2008;22(15):1897-1908.

61. Bunnell R, Opio A, Musinguzi J, et al. HIV transmission risk behavior among HIV-infected adults in Uganda: results of a nationally representative survey. AIDS. 2008;22(5):617-624.

62. Harries AD, Schouten EJ, Libamba E. Scaling up antiretroviral treatment in resource-poor settings. Lancet. 2006;367(9525):1870-1872.

63. Ho DD. Time to hit HIV, early and hard. N Engl J Med. 1995;333(7): 450-451.

64. Phillips A. Morbidity and mortality in the HAART era [abstract]. 15th Conference on Retroviruses and Opportunistic Infections (CROI 2008); 2008 Feb 3-6; Boston, MA, USA.

65. Hargrove JW, Humphrey JH. Mortality among HIV-positive postpartum women with high CD4 cell counts in Zimbabwe. AIDS. 2010;24(3): F11-F14.

66. May RM, Anderson RM. The transmission dynamics of human immunodeficiency virus (HIV). Philos Trans R Soc Lond B Biol Sci. 1988;321(1207):565-607. 
67. Williams BG, Korenromp EL, Gouws E, Schmid GP, Auvert B, Dye C. HIV infection, antiretroviral therapy, and $\mathrm{CD}^{+}$cell count distributions in African populations. J Infect Dis. 2006;194(10):1450-1458.

68. Cia.gov. c2007. Available from: https://www.cia.gov/. Accessed Aug 19 2010.

69. Assefa Y, Lera M. Universal voluntary HIV testing and immediate antiretroviral therapy [correspondence]. Lancet. 2009;373(9669):1080.

70. Cohen J. AIDS research. Treat everyone now? A 'radical' model to stop HIV's spread. Science. 2008;322(5907):1453.

71. Yu JK, Chen SC, Wang KY, et al. True outcomes for patients on antiretroviral therapy who are "lost to follow-up" in Malawi. Bull World Health Organ. 2007;85(7):550-554.

72. Mills EJ, Nachega JB, Buchan I, et al. Adherence to antiretroviral therapy in sub-Saharan Africa and North America: a meta-analysis. JAMA. 2006;296(6):679-690.

73. Farmer P, Léandre F, Mukherjee JS, et al. Community-based approaches to HIV treatment in resource-poor settings. Lancet. 2001;358(9279):404-409.

74. Garnett GP, Baggaley RF. Treating our way out of the HIV pandemic: could we, would we, should we? Lancet. 2009;373(9657):9-11.
75. Van Leth F, Phanuphak P, Ruxrungtham K, et al. Comparison of first-line antiretroviral therapy with regimens including nevirapine, efavirenz, or both drugs, plus stavudine and lamivudine: a randomised open-label trial, the 2NN Study. Lancet. 2004;363(9417):1253-1263.

76. Yerly S, Jost S, Telenti A, et al. Infrequent transmission of HIV-1 drugresistant variants. Antivir Ther. 2004;9(3):375-384.

77. Routy JP, Machouf N, Edwardes MD, et al. Factors associated with a decrease in the prevalence of drug resistance in newly HIV-1 infected individuals in Montreal. AIDS. 2004;18(17):2305-2312.

78. Jürgens R, Cohen J, Tarantola D, Heywood M, Carr R. Universal voluntary HIV testing and immediate antiretroviral therapy [correspondence]. Lancet. 2009;373(9669):1079.

79. Granich RM, Gilks CF, Dye C, de Cock KM, Williams BG. Universal voluntary HIV testing and immediate antiretroviral therapy - author's reply [correspondence]. Lancet. 2009;373(9669):1080-1081.

80. Corbett EL, Marston B, Churchyard GJ, de Cock KM. Tuberculosis in sub-Saharan Africa: opportunities, challenges, and change in the era of antiretroviral treatment. Lancet. 2006;367(9514):926-937.

81. Williams BG, Dye C. Antiretroviral drugs for tuberculosis control in the era of HIV/AIDS. Science. 2003;301(5639):1535-1537.
HIV/AIDS - Research and Palliative Care

\section{Publish your work in this journal}

HIV/AIDS - Research and Palliative Care is an international, peerreviewed open-access journal focusing on advances in research in HIV, its clinical progression and management options including antivira treatment, palliative care and public healthcare policies to contro viral spread. The journal welcomes original research, basic science,

\section{Dovepress}

clinical \& epidemiological studies, reviews \& evaluations, expert opinion \& commentary, case reports \& extended reports. The manuscript management system is completely online and includes a very quick and fair peer-review system. Visit http://www.dovepress.com/ testimonials.php to read real quotes from published authors. 